\title{
Prediction of vertical ionization potentials for organic compounds by integral characteristics of optical spectra and the number of protons in molecules
}

\author{
(C) Mikhail Yu. Dolomatov, ${ }^{1,2 *}$ Kamil F. Latypov, ${ }^{1}$ and Ella A. Kovaleva ${ }^{2+}$ \\ ${ }^{1}$ Institute of Physics and Technology of Bashkir State University. Zaki Validi St., 32. Ufa, 450074. \\ Bashkortostan Republic.Russia.Phone:+7 (917) 453-85-16.E-mail: milana.1992@mail.ru \\ ${ }^{2}$ Ufa State Petroleum Technological University. Kosmonavtov St., 1. Ufa, 450062. \\ Bashkortostan Republic. Russia.
}

\begin{abstract}
*Supervising author; ${ }^{+}$Corresponding author
Keywords: plural optical spectrums, descriptors, Structure - Property, electronic structure, number of protons, number of electrons, ionization potential, nitrogen-containing compounds, oxygen-containing compounds.
\end{abstract}

Abstract

In this review, the authors summarize the results of the first vertical ionization potentials with the structural and spectral integral descriptors of organic compounds: the integral oscillator strength defined in the visible or UV regions of the spectrum and the total number of protons in organic molecules. The adequate non-linear regression models relating the potentials of ionization as functions of the integral oscillator strength in the range between $6.53 \mathrm{eV}$ and $1.63 \mathrm{eV}$ (from 190 to $760 \mathrm{~nm}$ ) and the total number of protons in organic molecules. The regularities were allowing to estimate the first ionization potentials for organic oxygen - and nitrogen-containing compounds established. The established regularities are interpreted as the influence of exchange and electrostatic interactions on the energies of the highest occupied molecular orbitals. The ionization potentials were calibrated according to the method of Hartree-Fock (RHF) method using 6-31G(d,p) basis set from the Koopmans' theorem. The obtained models allow us to estimate first ionization potentials of organic oxygen-and nitrogen-containing molecular systems by the integral oscillator strength and by the number of protons with an accuracy of 0.4 to $9 \%$. This accuracy is quite suitable for practical applications. The research results can be used in chemistry, photochemistry, molecular electronics, photonics, and physical chemistry to study electron transfer processes, the characteristics of the band structure of nanoparticles. The present paper examples confirmed by statistical data processing.

\section{References}

[1] O.A. Reutov, A.L. Kurts, and K.P. Butin. Organic Chemistry Textbook. Izd. MGU, Moscow. 1999. 2292p. (russian)

[2] N.F. Stepanov. Quantum mechanics and quantum chemistry. Moscow: Mir. 2001. 519p. (russian)

[3] V.I. Vovna. Photoelectron spectroscopy of molecules. Soros educational journal. 1999. No.1. P.86-91. (russian)

[4] L.V. Gurvich, G.V. Karachevtsev, V.N. Kondrat'ev, Yu.A. Lebedev, V.A. Medvedev, V.K. Potapov, and Yu.S. Khodeev. Dissociation Energies of Chemical Bonds, Ionization Potentials, and Electron Affinities. Moscow: Nauka. 1974. 351p. (russian)

[5] M.Yu. Dolomatov, E.A. Kovaleva, K.F. Latypov, M.M. Dolomatova, N.Kh. Paymurzina, and G.U. Yarmuhametova. Integral characteristics of optical spectra, as a new class of descriptors for complex molecular systems. Butlerov Communications. 2019. Vol.57. No.1. P.1-14. DOI: 10.37952/ROI-jbc01/19-57-1-1

[6] M.Yu. Dolomatov, G.R. Mukaeva. Journal of Applied Spectroscopy. 1992. Vol.56. No.4. P.570-574. (russian)

[7] M.Yu. Dolomatov, G.R. Mukaeva, D.O. Shulyakovskaya. Electron Phenomenological Spectroscopy and its Application in Investigating Complex Substances in Chemistry, Nanotechnology and Medicine. Journal of Materials Science and Engineering B. 2013. Vol.3. No.3. P.183-199.

[8] M.Yu. Dolomatov, D.O. Shulyakovskaya, G.R. Mukaeva, G.U. Jarmuhametova, K.F. Latypov. Simple characteristics estimation methods of material and molecule electronic structure. Journal of Materials Science and Engineering B. 2012. No.4. P.261-268. 
[9] M.Yu. Dolomatov, E.A. Kovaleva. Journal of Structural chemistry. 2015. Vol.56. No.5. P.887- 893. (russian)

[10] M.Yu. Dolomatov, K.F. Latypov. Photonics. 2017. Vol.64. No.4. P.60-67. (russian)

[11] M.Yu. Dolomatov, N.H. Paymurzina, and E.A. Kovaleva. Evaluation of donor-acceptor properties of polycyclic hydrocarbon molecules by the integral autocorrelation characteristics of the optical spectra. Butlerov Communications. 2018. Vol.53. No.2. P.28-37. DOI: 10.37952/ROI-jbc-01/18-53-2-28

[12] M.Yu. Dolomatov, G.U. Yarmuhametova, D.O. Shulyakovskaya. Applied Physics. 2011. No.1. P.20-31. (russian)

[13] M.A. Elyashevich. Atomic and molecular spectroscopy. Moscow, Editorial URSS. 2001. 896p. (russian)

[14] G.F. Bol'shakov, V.S. Vatago, and F.B. Agrest. Ultraviolet Spectra of Heteroorganic Compounds. Leninigrad: Chemistry. 1969. 504p. (russian)

[15] Atlas of Spectra of Organic Compounds. Issue 13. Absorption Spectra of 9,10-Anthraquinone Derivatives in the Infrared, Ultraviolet, and Visible Regions. Ed. V.A. Koptyug. Novosibirsk: Inst. Org. Khim. Sib. Otd. Akad. Nauk SSSR. 1967. 116p. (russian) 